\title{
1 Unlocking inaccessible historical genomes preserved in formalin
}

3 Erin E. Hahn ${ }^{1}$, Marina R. Alexander ${ }^{1}$, Alicia Grealy ${ }^{1}$, Jiri Stiller ${ }^{2}$, Donald M. Gardiner ${ }^{2}$ and

4 Clare E. Holleley ${ }^{1 *}$

6 Institutional Addresses:

$7 \quad{ }^{1}$ National Research Collections Australia, Commonwealth Scientific Industrial Research

8 Organisation, Canberra, ACT 2601, Australia

$92{ }^{2}$ Agriculture and Food, Commonwealth Scientific Industrial Research Organisation, St Lucia,

10 Queensland 4067, Australia

12 Email addresses:

13 EEH - erin.hahn@csiro.au; MRA - marina.alexander@csiro.au; AG -

14 Alicia.grealy@csiro.au; JS - jiri.stiller@csiro.au; DMG - Donald.gardiner@csiro.au; CEH -

15 clare.holleley@csiro.au*

$16 *$ Corresponding author 


\section{Abstract}

\section{Background}

19 Museum specimens represent an unparalleled record of historical genomic data. However, the

20 wide-spread practice of formalin preservation has thus far impeded genomic analysis of a large

21 proportion of specimens. Limited DNA sequencing from formalin-preserved specimens has

22 yielded low genomic coverage with unpredictable success. We set out to refine sample 23 processing methods and to identify specimen characteristics predictive of sequencing success.

24 With a set of taxonomically diverse specimens collected between 1936 and 2015 and ranging

25 in preservation quality, we compared the efficacy of several end-to-end whole genome 26 sequencing workflows alongside a k-mer-based trimming-free read alignment approach to

27 maximize mapping of endogenous sequence.

\section{Results}

29 We recovered complete mitochondrial genomes and up to $3 \mathrm{X}$ nuclear genome coverage from

30 formalin-fixed tissues. Hot alkaline lysis coupled with phenol-chloroform extraction out-

31 performed proteinase $\mathrm{K}$ digestion in recovering DNA, while library preparation method had

32 little impact on sequencing success. The strongest predictor of DNA yield was overall

33 specimen condition, which additively interacts with preservation conditions to accelerate DNA

34 degradation.

\section{Conclusions}

36 We demonstrate a significant advance in capability beyond limited recovery of a small number

37 of loci via PCR or target-capture sequencing. To facilitate strategic selection of suitable

38 specimens for genomic sequencing, we present a decision-making framework that utilizes

39 independent and non-destructive assessment criteria. Sequencing of formalin-fixed specimens

40 will contribute to a greater understanding of temporal trends in genetic adaptation, including

41 those associated with a changing climate. Our work enhances the value of museum collections 
bioRxiv preprint doi: https://doi.org/10.1101/2021.04.18.440380; this version posted April 20, 2021. The copyright holder for this preprint

(which was not certified by peer review) is the author/funder, who has granted bioRxiv a license to display the preprint in perpetuity. It is made available under aCC-BY-NC 4.0 International license.

42 worldwide by unlocking genomes of specimens that have been disregarded as a valid molecular

43 resource.

44

45 Keywords: DNA, formaldehyde, formalin-fixed, genome, hot alkali, museum, museomics,

46 preservation media 


\section{Background}

48 Natural history collections are a window into the recent past, offering a view of historical

49 biodiversity that is unparalleled in its detail. Collected over the last 250 years, voucher specimens document a period of time over which humans have had a devastating impact on the natural world (1). The comprehensive metadata associated with each specimen (collection date, location, sex, weight, age, etc.), phenotypic data (e.g., color, size, gut contents) and genomic data can be used to monitor ecosystem health and study the mechanisms driving adaptation, evolution, speciation and extinction $(2,3)$. The value of collections as sources of historical genetic material has been recognized for the past 30 years, with numerous pathways emerging to retrieve high-quality DNA from challenging archival vertebrate tissues such as skins (4),

57 feathers $(5,6)$, eggshells $(7,8)$ and toe pads $(9)$.

DNA degradation associated with preservation method and aging has limited most genetic studies of museum specimens to interrogation of relatively few loci via PCR amplification, often targeting the high copy mitochondrial genome. For phylogenetic studies where a survey of many-fold more loci improves understanding of species' evolutionary history (10-12), genome-wide analyses are increasingly becoming common place. With demand for historical genome-wide data on the rise, newly-developed target-capture approaches now facilitate broader genomic survey from degraded museum specimens (13-15). In some cases, recovery and assembly of whole historical genomes has been achieved $(16,17)$, including, extinct from species (e.g., the Tasmanian tiger (18)). While technological advances are enabling recovery

67 of genomic data from many museum specimens, genomic study of those preserved with $10 \%$ 68 formalin (3.4\% w/v formaldehyde) has thus far been very limited.

69 Formalin-fixation, followed by storage in ethanol, is a common curatorial method used to preserve soft tissue structure. Of the 1.9 million records of preserved chordates within the open- 
access Atlas of Living Australia (ALA) specimen database (19), 33\% are classified as "spirit"formalin" preparation within the ALA's chordate records indicates at least $4 \%$ of specimens $(\mathrm{N}=77,301)$ have been formalin-fixed. This is likely a severe underestimate because formalinfixation is not consistently recorded by all collections. Notably, for fish, reptiles and amphibians, formalin-fixation has historically been the primary method used to preserve tissues long-term while mammals and birds are commonly dry-preserved. Most collections now archive frozen fresh tissue specifically as a genomic resource. However, prior to the 1980s, spirit-preservation was the only method used to preserve soft tissue. Thus, spirit collections offer the only opportunity to obtain genetic data from a large proportion of older specimens, holotypes and some of the world's most biodiverse vertebrate taxonomic groups.

Genomic study of formalin-preserved museum specimens has lagged behind because DNA extracted from such tissues is typically low-yield and highly fragmented. PCR amplification of formalin-degraded DNA templates is generally restricted to few, short genomic loci, which provide limited phylogenetic resolution (20). Formalin fixation presents further challenges by inducing numerous molecular lesions, such as strand breaks, base misincorporation, and both intra- and intermolecular cross-links (21-23). Formaldehyde damage to DNA templates can result in sequencing artefacts that are difficult to differentiate from true genetic variants $(22,23)$. Because PCR amplification of damaged DNA is particularly prone to sequencing artefacts, it is preferable to perform deep next-generation sequencing of amplicons (20) or to

91 avoid amplicon approaches altogether through whole genome sequencing (WGS) of degraded templates (24). Coupled with library preparation methods optimized for low-input and

93 damaged DNA templates $(25,26)$, high-throughput sequencing can generate enough coverage

94 to call genomic variants with high confidence (27). Thus, WGS and reduced representations of 
genomes could provide a way to overcome the challenges associated with formalin damage and accurately reconstruct historical genetic variation from formalin-preserved tissues.

97 Promisingly, WGS of formalin-fixed paraffin-embedded (FFPE) archival tissues has become

98 routine in clinical and medical contexts (28). However, museum specimens are often older, 99 exposed to higher concentrations of formaldehyde, incubated in the fixative for longer (29) and

100 in most cases have not been preserved in ideal conditions. Common museum practices, such

101 as failure to rinse specimens prior to permanent storage in ethanol, result in prolonged

102 formaldehyde exposure (30). Indeed, many specimens can be in contact with formaldehyde (or 103 its derivatives, such as formic acid) for the entirety of their tenure in a collection. Prolonged 104 formaldehyde exposure, especially under acidic conditions, is thought to result in more extreme 105 DNA degradation (20,31). The damage resulting from the preservation process compounds 106 with DNA damage due to natural decomposition, which can be extensive and often precedes 107 any obvious visual indicators of decomposition (32). Unfortunately, the time between death 108 and preservation (post-mortem interval) is highly variable and rarely recorded. In light of these 109 additional challenges, WGS methods used with FFPE tissues are relevant but not directly 110 transferable to formalin-fixed museum tissues.

111 Of the few genetic studies of formalin-fixed museum specimens, most have targeted nuclear 112 (33-37) and high copy mitochondrial $(20,38,39)$ loci via PCR amplification due to the 113 difficulty and unpredictability of nuclear DNA extraction. There are few examples of broader114 scale genomic sequencing of formalin-fixed museum specimens and none have recovered 115 whole vertebrate genomes. Hot alkaline extraction followed by WGS of a single 30-year-old 116 formalin-preserved Anolis lizard yielded sufficient coverage to reconstruct the entire 117 mitochondrial genome (40). Using the same method, whole genomes were recovered for the 118 bioluminescent bacterial symbionts contained within light organs of formalin-preserved 119 cardinalfish (41). Using a proteinase K digestion method, sufficient gDNA was recovered for 
capture and sequencing of ultra-conserved elements from formalin-preserved snakes (42).

121 Hybridization capture baits have also been used to recover the mitochondrial genome from a

122 120-year-old formalin-preserved Crimean green lizard (43). Highlighting the difficulty of

123 recovering gDNA from formalin-preserved specimens, numerous studies have reported failure

124 to extract and amplify gDNA from formalin-preserved museum tissues $(20,44,45)$. In this context, it is unfortunate yet wise to be hesitant to conduct destructive sampling of formalinpreserved specimens for the purposes of costly WGS.

127 Recent reports of successful, albeit limited, genomic sequencing in formalin-preserved 128 specimens indicate WGS of higher quality specimens is possible. However, without a

129 framework to guide specimen selection, genomic work on formalin-preserved museum tissues

130 will remain infeasible. It is likely impossible to fully know the numerous and interdependent

131 factors driving sequencing success (e.g., age of the specimen $(46,47)$, method of preservation

132 (48), post-mortem interval (32) and heat and light exposure during storage). However, 133 identification of metrics with which to pre-screen specimens for sequencing suitability will 134 improve yield of genomic data while reducing unnecessary destruction of specimens. With 135 screening criteria in hand, museum curators will be less reluctant to grant destructive sampling 136 (49) and researchers will be more inclined to include historical specimens in their analyses.

137 To facilitate informed-selection of formalin-preserved museum specimens for WGS, we set 138 out to further refine appropriate extraction and library preparation methods and to identify 139 specimen characteristics predictive of DNA extraction and sequencing success. First, we 140 investigated the relationship between residual formaldehyde concentration and $\mathrm{pH}$ in 141 preservation media through a survey of specimens in the Australian National Wildlife 142 Collection (ANWC; Crace, Australia). Next, in a phased approach, we compared DNA yield 143 achieved with three extraction methods - (1) hot alkaline lysis digestion followed by phenol144 chloroform extraction, (2) proteinase $\mathrm{K}$ digestion followed by phenol-chloroform extraction 
and (3) proteinase $\mathrm{K}$ digestion followed by silica spin column purification. We then applied

146 the best-performing DNA extraction method to terrestrial vertebrate specimens representing

147 the broad range of tissue quality observed in museum specimens and tested performance of two

148 library preparation methods - (1) single-stranded method v2.0 (ss2) (25) and (2) BEST double-

149 stranded method (dsBEST) (26). Placing our results into context with a comprehensive and

150 unbiased survey of collection-wide spirit preservation conditions, we present a decision-

151 making framework to accelerate and facilitate genomic research using formalin-preserved

152 specimens.

\section{Results}

\section{Preservation media condition survey}

156 Within 149 ANWC specimen jars surveyed (23 amphibian, 40 mammal, 40 reptile, and 46 avian), preservation media $\mathrm{pH}$ ranged from 4.8-8.4 with $70(47 \%), 61(41 \%)$ and $18(12 \%)$ having neutral (6.5-7.5), low $(<6.5)$ and high $(>7.5) \mathrm{pH}$, respectively. Residual formaldehyde concentration ([F]) ranged from 0-40,000 mg/L. High $[\mathrm{F}](>1000 \mathrm{mg} / \mathrm{L})$ was detected in $61 \%$

160 of low $\mathrm{pH}$ jars, $6 \%$ of neutral $\mathrm{pH}$ jars and $0 \%$ of high $\mathrm{pH}$ jars. We assumed specimens in jars 161 yielding $[\mathrm{F}]=0(\mathrm{n}=82)$ were preserved with ethanol and without exposure to formaldehyde.

162 Consistent with the practice of fixing specimens with unbuffered formalin combined with the 163 gradual degeneration of formaldehyde to formic acid, the $\mathrm{pH}$ of the formalin-preserved samples 164 (range 4.8-7.1; mean $=6.2$ ) was significantly lower than for the ethanol-preserved samples 165 (range 6.1-8.4; mean $=7.1)($ T-test; $p<0.0001$; Supplementary Figure 1A). The recorded collection date of the specimens ranged from 1936-2015. The time since collection (age) of the ethanol-preserved specimens (mean $=40.1$ years) was not significantly different than the formalin-preserved specimens $($ mean $=36.1$ years $)($ Supplementary Figure $1 \mathrm{~B})$. Among the 
169 formalin-preserved samples, $[\mathrm{F}]$ and $\mathrm{pH}$ were negatively correlated $(\mathrm{R}=-0.6, \mathrm{p}<0.001$; Figure

170 1). Age was not significantly correlated with either [F] or $\mathrm{pH}$. Of the 12 specimens selected for 171 sequencing, collection date ranged from 1962-2006 and $\mathrm{pH}$ ranged from 4.9-8.2. Three

172 sequenced specimens were ethanol-preserved and nine sequenced specimens were formalin173 preserved with $[\mathrm{F}]$ ranging from $325-20,000 \mathrm{mg} / \mathrm{L}$ (Table 1).

Table 1. Specimen metadata and independently assessed preservation quality metrics for samples selected for sequencing

177 Twelve specimens (three ethanol-preserved and nine formalin-preserved) from the ANWC 178 spirit vault were selected for DNA extraction and sequencing. Unique ANWC specimen IDs, 179 species names, common name, recorded year of collection, residual formaldehyde 180 concentration in the preservation media $(\mathrm{mg} / \mathrm{L}), \mathrm{pH}$ and tissue sampled for extraction are 181 given.

\begin{tabular}{|c|c|c|c|c|c|c|c|}
\hline Preservation & Specimen ID & Species name & Common name & Collection year & {$[\mathbf{F}](\mathrm{mg} / \mathrm{L})$} & pH & Tissue sampled \\
\hline \multirow{3}{*}{ Ethanol } & ANWC B30438 & Phalacrocorax carbo & Great black cormorant & 1977 & 0 & 8.2 & Skin \\
\hline & ANWC B00001 & Aquila audax & Wedge-tailed eagle & 1973 & 0 & 7.68 & Liver \\
\hline & ANWC M15492 & Phascolarctos cinereus & Koala & 1971 & 0 & 7 & Muscle \\
\hline \multirow{9}{*}{ Formalin } & ANWC A02522 & Rhinella marina & Cane toad & 2002 & 2050 & 6.41 & Liver \\
\hline & ANWC M11465 & Macropus eugenii & Tammar wallaby & 1989 & 8000 & 5.26 & Liver \\
\hline & ANWC R03280 & Crocodylus porosus & Saltwater crocodile & 1973 & 4000 & 6.31 & Liver \\
\hline & ANWC B47838 & Melopsittacus undulatus & Budgerigar & 1996 & 5000 & 6.3 & Liver \\
\hline & ANWC R06312 & Pogona minima & Dwarf dragon & 1986 & 1800 & 7.04 & Liver \\
\hline & ANWC R01545 & Pogona vitticeps & Central dragon & 1971 & 325 & 6.24 & Liver \\
\hline & ANWC B40690 & Taeniopygia guttata & Zebra finch & 1986 & 20000 & 4.86 & Muscle \\
\hline & ANWC B34691 & Falco cenchroides & Australian kestrel & 2006 & 2000 & 5.45 & Liver \\
\hline & ANWC M03973 & Ornithorhynchus anatinus & Platypus & 1962 & 10000 & 5.79 & Muscle \\
\hline
\end{tabular}

182 
DNA quantification

184 We compared DNA yield from the hot alkaline lysis (HA), proteinase K plus phenol185 chloroform (proK-PC) and proteinase K plus column (proK-col) extraction methods for the

186 Rhinella marina, Macropus eugenii and Crocodylus porosus specimens and observed no 187 significant differences between extraction methods (one-way ANOVA; Supplemental Figure 188 3A). However, the HA method produced more DNA from the two poor quality specimens $(M$. 189 eugenii and C. porosus) compared to either of the proteinase K methods (Table 2). Thus, we 190 predicted the HA method would perform better on specimens ranging broadly in preservation 191 quality and we used this method to extract the remaining nine specimens. HA extraction yielded 192 DNA detectable by high sensitivity Qubit for all twelve specimens. Two ethanol-preserved specimens (Aquila audax and Phascolarctos cinereus) and two formalin- preserved specimens (R. marina and Melopsittacus undulatus) yielded $>1,000 \mathrm{ng}$ total DNA from $50 \mathrm{mg}$ of tissue (Table 2). Three specimens, Phalacrocorax carbo, Taeniopygia guttata and Ornithorhynchus anatinus, yielded particularly low (<100 ng) total DNA from $50 \mathrm{mg}$ of tissue (Table 2$)$. We observed no significant difference in DNA yield between ethanol and formalin-preserved specimens (T-test; Supplemental Figure 3B). However, mean DNA yield from ethanolpreserved specimens was more than double that from formalin-preserved specimens. Mean DNA yield from formalin-preserved specimens in preservation media with low $\mathrm{pH}(<6)$ was not significantly different from those in media with neutral to high $\mathrm{pH}(>6)$ (Supplemental

202 Figure 3C). DNA yield was significantly higher from formalin-preserved liver tissue compared to non-liver tissue (T-test; $\mathrm{p}<0.05$; Supplemental Figure 3D). Both $[\mathrm{F}]$ and age showed a negative but non-significant correlation with DNA yield from formalin-preserved specimens

205 (Supplemental Figures 3E and 3F). 
Table 2. Sequencing and alignment statistics

207 For all specimens, DNA yield is given for the individual extractions of $50 \mathrm{mg}$ of tissue. For

208 the remaining metrics, the values shown were calculated having combined both the ss2 and

209 dsBEST libraries. The number of raw reads is given as a sum of all single reads (R1 and R2)

210 from the paired-end sequencing run. Reads aligned indicates the percent of raw reads aligned

211 to reference genome after removal of PCR and optical duplicates. The mean aligned insert

212 length is the mean length (in bp) of the aligned portion of the read. $\mathrm{C}_{\text {nuc }}$ is the coverage of the

213 nuclear genome. $\mathrm{C}_{\mathrm{mt}}$ is the proportion of mitochondrial genome with greater than $30 \mathrm{X}$

214 coverage. $\mathrm{C}_{\text {pot }}$ is the estimated potential genomic coverage if the full library had been

215 sequenced, calculated from the estimated library complexity. MRM is the number of reads

216 aligned to the mitochondrial genome per one million raw reads.

\begin{tabular}{|c|c|c|c|c|c|c|c|c|c|c|}
\hline Preservation & Species & $\begin{array}{c}\text { Extraction } \\
\text { method }\end{array}$ & $\begin{array}{l}\text { DNA yield } \\
\text { from } 50 \mathrm{mg} \\
\text { (ng) }\end{array}$ & $\begin{array}{c}\text { Raw } \\
\text { reads } \\
\text { (million) }\end{array}$ & $\begin{array}{c}\text { Reads } \\
\text { aligned } \\
(\%)\end{array}$ & $\begin{array}{l}\text { Mean aligned } \\
\text { insert length } \\
\text { (bp) }\end{array}$ & $\mathbf{C}_{\text {nuc }}$ & $\mathbf{C}_{\mathrm{mt}}$ & $\mathrm{C}_{\text {pot }}$ & MRM \\
\hline & & HA & 1,860 & 434 & 21 & 65 & 2.2 & 0.78 & 6.2 & 52 \\
\hline & Rhinella marina & proK-col & 666 & 77 & 40 & 81 & 1 & 0 & 6.2 & 14 \\
\hline & & proK-PC & 2,550 & 321 & 15 & 74 & 1.2 & 0.42 & 11.4 & 29 \\
\hline & & HA & 271 & 306 & 8 & 56 & 0.5 & 0.59 & 2.7 & 50 \\
\hline & Macropus eugenii & proK-col & 4 & 17 & 1 & 67 & 0 & 0 & 0.1 & 3 \\
\hline & & proK-PC & 33 & 801 & $<1$ & 65 & 0 & 0 & 0.1 & 2 \\
\hline & & HA & 130 & 23 & $<1$ & 67 & 0 & 0 & 0 & 11 \\
\hline \multirow[t]{9}{*}{ Formalin } & Crocodylus porosus & proK-col & None detected & 160 & $<1$ & 70 & 0 & 0 & 0.1 & 12 \\
\hline & & proK-PC & 79 & 294 & $<1$ & 62 & 0 & 0 & 0 & 2 \\
\hline & Melopsittacus undulatus & HA & 2,400 & 318 & 20 & 60 & 3.1 & 0.94 & 23.6 & 201 \\
\hline & Pogona minima & HA & 521 & 367 & 7 & 58 & 0.8 & 0.51 & 7.5 & 29 \\
\hline & Pogona vitticeps & HA & 672 & 432 & 15 & 59 & 2.1 & 0.85 & 7.9 & 52 \\
\hline & Taeniopygia guttata & HA & 15 & 62 & $<1$ & 66 & 0 & 0 & 0 & 1 \\
\hline & Falco cenchroides & HA & 690 & 303 & 5 & 56 & 0.7 & 0.12 & 2.1 & 14 \\
\hline & Ornithorhynchus anatinus & HA & 22 & 520 & $<1$ & 70 & 0 & 0.13 & 0.8 & 20 \\
\hline & Phalacrocorax carbo & HA & 57 & 292 & $<1$ & 69 & 0.10 & 0.90 & 0.60 & 50.00 \\
\hline \multirow[t]{2}{*}{ Ethanol } & Aquila audax & HA & 1,932 & 282 & 67 & 76 & 11.3 & 0.98 & 323 & 2515 \\
\hline & Phascolarctos cinereus & HA & 1,254 & 423 & 60 & 76 & 5.4 & 0.94 & 93 & 2606 \\
\hline
\end{tabular}




\section{Pre-alignment library quality assessment}

218 Prior to alignment, we used FastQC to assess the quality of paired-end reads from ss2 and

219 dsBEST libraries. All libraries contained a high proportion of adapter content and low read

220 quality score beginning at roughly $50 \mathrm{bp}$, consistent with highly fragmented input DNA.

221 Focusing on the first $75 \mathrm{bp}$ of the raw reads, mean sequence quality was slightly but significantly higher for read $2($ mean Phred score $=34.3)$ than for read $1($ mean Phred score $=$ read 1 (mean of the differences $=2.1$; paired T-test; $p<0.001)$ and read 2 (mean of the differences $=0.79$; paired T-test; $\mathrm{p}<0.01$ ). Mean sequence quality was not significantly different between reads derived from ethanol and formalin-preserved tissues, even when evidence of cross-contamination in several libraries prepared from low DNA yield extractions. Compared to negative controls, both $O$. anatinus libraries and all but two C. porosus libraries showed a higher number of reads classified as genus Mus by Kraken2 (Supplementary Table the least DNA. The O. anatinus HA extraction yielded just $22 \mathrm{ng}$. The C. porosus HA and proK-PC extractions yielded 130 and 79 ng, respectively, while the proK-col extraction yielded no detectable DNA. The only other specimens to yield less than 500 ng were the $P$. carbo, $T$. guttata and M. eugenii.

\section{Relative alignment quality from three extraction methods}

239 We used three indicators of alignment quality to compare the relative success of the three

240 extraction methods on the $R$. marina, M. eugenii and $C$. porosus specimens: percent of raw reads aligned to the genome ( $\%$ alignment), the number of reads aligned to the mitochondrial 
genome per million raw reads (MRM) and the mean aligned insert length. Among these three of the three alignment quality indicators (paired T-tests). Therefore, we took the mean of the two library preparations to compare extraction methods across each alignment quality indicator. Again, we observed no significant difference between the three extraction methods applied to the $R$. marina, M. eugenii and $C$. porosus specimens in any of the three alignment

(Figure 2A and Table 2), indicating failure of all extraction and library preparation methods on

this specimen. Excluding the C. porosus libraries, we observed significant differences in MRM

between the extraction methods (one-way ANOVA; $p<0.05$ ) with the HA method producing significantly more MRM than both the proK-col and proK-PC methods (Tukey tests; $\mathrm{p}<0.05$ ).

We observed no significant difference in MRM between the proK-col and proK-PC methods (Tukey tests) nor in \% alignment or mean insert length between the three extraction methods (one-way ANOVA).

Effect of specimen quality on sequencing success

257 The percentage of aligned reads removed by optical and PCR de-duplication varied between $8.8 \%$ and $99.5 \%$ across all libraries. Among the HA alignments, de-duplication reduced significantly more mapped reads from dsBEST libraries than from ss2 libraries (paired T-test; $\mathrm{p}<0.01)$. Combining the ss2 and dsBEST libraries for each HA extraction, de-duplication removed more than double the percentage of reads $(69.8 \%$ versus $32.8 \%)$ from poor quality specimens (those yielding $<1 \%$ reads aligned) compared to better quality specimens (those yielding $>1 \%$ reads aligned). However, this difference was not significant (T-test). Deduplication removed significantly more reads from the formalin-preserved specimens (mean $=$

$26554.6 \%)$ than from the ethanol-preserved specimens (mean $=16.7 \%)(T$-test; $\mathrm{p}<0.01)$. 
the dsBEST and ss2 HA libraries, respectively. Across all specimens extracted using the HA comparison of the effect of specimen quality on alignment success taking the mean of each alignment quality indicator from the two HA library preps.

HA extraction of one of three ethanol-preserved specimens ( $P$. carbo) and three of nine formalin-preserved specimens (C. porosus, T. guttata and O. anatinus) produced $<1 \%$ aligned reads (Table 2), indicating equal rates of very poor sequencing success with ethanol- and formalin-preserved tissues. Excluding the specimens with $<1 \%$ aligned reads, the ethanolpreserved specimens produced a significantly higher percentage of aligned reads (T-test; $\mathrm{p}<$ 0.01). Two of the three ethanol-preserved specimens (A. audax and P. cinereus) produced $>$ $60 \%$ aligned reads while the remaining six formalin-preserved specimens ( $R$. marina, $M$. eugenii, M. undulatus, Pogona minima, Pogona vitticeps and Falco cenchroides) produced

280 between $5 \%$ and $21 \%$ aligned reads (Table 2). Excluding the specimens with $<1 \%$ aligned reads, the mean insert length was significantly longer for the ethanol-preserved specimens

$282($ mean $=76 \mathrm{bp})$ compared to the formalin-preserved specimens $($ mean $=59 \mathrm{bp})(\mathrm{T}$-test; $\mathrm{p}<$ 283 0.0001). MRM was also significantly higher for the ethanol-preserved specimens (mean = $2842,560)$ compared to the formalin-preserved specimens $($ mean $=43)($ T-test: $p<0.01)$.

285 The percentage of reads aligned increased with preservation media $\mathrm{pH}(\mathrm{R}=0.44$; Figure $3 \mathrm{~A})$, 286 decreased with preservation media $[\mathrm{F}](\mathrm{R}=-0.53$; Figure $3 \mathrm{~B})$ and decreased with specimen 287 age ( $\mathrm{R}=-0.46$; Figure $3 \mathrm{C})$, although these correlations were not statistically significant. The 288 percentage of aligned reads was significantly higher in specimens sampled with liver than those 289 sampled with muscle and skin (T-test; $\mathrm{p}<0.05$; Figure 3D). Of the specimens yielding poor 290 sequencing success ( $<1 \%$ reads aligned), all but $C$. porosus were sampled with either muscle 
or skin as liver was not present. The only specimen sampled with a tissue other than liver to

292 yield a percent of reads aligned $>1 \%$ was the ethanol-preserved $P$. cinereus.

\section{Genome sequencing coverage}

294 Nuclear genome coverage $\left(\mathrm{C}_{\text {nuc }}\right)$ of the deduplicated alignments was $<1 \mathrm{X}$ for the majority of libraries. Since raw read yield was highly variable, $\mathrm{C}_{\text {nuc }}$ is not an appropriate measure with which to compare the extraction or library preparation methods. However, it is noteworthy that we achieved $\mathrm{C}_{\text {nuc }}>1 \mathrm{X}$ for two of the ethanol-preserved specimens and three of formalinpreserved specimens. Combining all libraries for a given specimen, we achieved a total of 5.4X and $11.3 \mathrm{X} \mathrm{C}_{\mathrm{nuc}}$ for the ethanol-preserved $P$. cinereus and $A$. audax specimens, respectively

300 (Table 2). Likewise, we achieved a total of 2.1X, 3.1X and 4.4X $\mathrm{C}_{\text {nuc }}$ for the formalin-preserved P. vitticeps, M. undulatus and R. marina specimens, respectively (Table 2). To estimate the potential for improving $\mathrm{C}_{\text {nuc }}$ through re-sequencing of the prepared libraries, we calculated potential genomic coverage $\left(\mathrm{C}_{\mathrm{pot}}\right)$ (Table 2$)$. Combining all libraries for a given specimen, $\mathrm{C}_{\text {pot }}$ exceeded 20X for the R. marina and M. undulatus and exceeded 75X for the P. cinereus and coverage $\left(\mathrm{C}_{\mathrm{mt}}\right)$ was nearly complete $(>0.9)$ for all three ethanol-preserved specimens (Table 2). $\mathrm{C}_{\mathrm{mt}}$ for the formalin-preserved M. undulatus (0.94) was comparable to that of the ethanol-

preserved specimens. $\mathrm{C}_{\mathrm{mt}}$ was moderate to high $(>0.5)$ for five of the formalin-preserved specimens (Table 2). Only the $C$. porosus, $T$. guttata, $F$. cenchroides and $O$. anatinus yielded very poor $\mathrm{C}_{\mathrm{mt}}(<0.15)$.

\section{Read length periodicity}

312 From the aligned insert lengths estimated with Picard, we plotted the frequency of reads

313 between 50 and 100 bp (Figure 4). This plot revealed a pattern of read length periodicity in 314 several specimens, notably those that resulted in higher mapping success. We observed 315 prominent periodicity of approximately $10.1 \mathrm{bp}$ in the $R$. marina specimen extracted with the 
316 proK-PC method. While less pronounced, we observed read length periodicity of

317 approximately $10.8 \mathrm{bp}$ in the HA extractions of $R$. marina, $P$. vitticeps, $P$. minima, $F$.

318 cenchroides, A. audax and P. cinereus. The pattern of periodicity was observed in both the

319 dsBEST and ss2 libraries, however, it was slightly more pronounced in the dsBEST libraries.

\section{Discussion}

321 In this study, we present evidence challenging the common perception that formalin-preserved

322 museum specimens are devoid of accessible DNA. Processed with a tailored molecular and

323 bioinformatic workflow, formalin-preserved specimens had an overall sequencing success rate

324 equivalent to ethanol-preserved specimens, albeit with recovery of a lower percentage of

325 sequence reads mapping to the reference genome. Contrary to popular belief, we found

326 genome-wide nuclear data is retrievable from some formalin-preserved museum specimens,

327 even with a moderate investment of sequencing effort (with $30 \%$ of formalin-preserved

328 specimens, we achieved $>2 \mathrm{X}$ nuclear genome coverage from 300-500 million raw reads). We

329 also show reconstruction of large sections of the mitochondrial genome is possible even in poor

330 quality specimens where limited nuclear data were recovered (with 55\% of formalin-preserved

331 specimens, we achieved $>30 \mathrm{X}$ coverage of more than $50 \%$ of the mitochondrial genome).

332 Investigating specimens covering a range of preservation quality, we also developed a decision-

333 making framework to improve sequencing success rate and prioritize suitable specimens. Our

334 findings support a considered and targeted sequencing approach that transforms thousands of

335 spirit collection specimens into a new molecular resource. Improved access to genomic data

336 held in these specimens has the potential to inform research into the mechanisms driving

337 adaptation, evolution, speciation and extinction. 
Hot alkaline lysis effectively recovers gDNA from formalin-preserved archival tissues suitable for next generation sequencing.

340 Originally developed for DNA extraction from FFPE sections, the HA method relies on high

341 heat $\left(120^{\circ} \mathrm{C}\right)$ under alkaline conditions $(\mathrm{pH}=13)$ to break strong inter- and intramolecular

342 cross links and utilizes organic extraction to maximize capture of fragmented gDNA from

343 formalin-preserved tissues (50-52). This method has been applied to museum specimens to

344 successfully recover sections of the mitochondrial genome in trout (53) and full mitochondrial

345 genomes from lizards (40) and bacterial symbionts (41). Here we show the HA yields gDNA

346 in adequate quantities for WGS from higher-quality formalin-preserved museum specimens.

347 Coupled with library preparation methods designed to efficiently convert degraded DNA, we

348 produced complex sequencing libraries with the potential to recover full vertebrate genomes

349 when mapped using a strategy optimized to maximize recovery of endogenous sequence. Our

350 results indicate that the HA method is appropriate for DNA extraction from a broad range of

351 taxa preserved under various conditions, making it well-suited for application in both museum

352 and pathological settings.

353 In a small-scale comparison to proK digestion with either phenol-chloroform extraction or

354 column purification, the HA method performed superiorly for poor quality formalin-preserved

355 specimens. We experienced equal success rates with the HA method in formalin and ethanol-

356 preserved tissues. It is not standard practice to apply the HA method to ethanol-preserved

357 specimens, which do not suffer from cross-linking, but we implemented it in this study to serve

358 as a comparison to formalin-fixed tissues. Thus, while the HA method is likely unnecessarily

359 harsh for recovery of DNA from tissues not crosslinked with formaldehyde, we propose this

360 extraction method is suitable across a wide range of tissue qualities and preservation conditions

361 observed in museum spirit collections. And, given that we achieved relatively high yield from

362 the ethanol-preserved tissues, we propose that the HA method is appropriate in cases where 
contact with formalin cannot be determined. We caution; however, the HA method's success our HA extraction of ethanol-preserved muscle tissue was less successful than our extraction of ethanol-preserved liver tissue. HA extraction has been previously observed to perform poorly compared to cetyltrimethylam-monium bromide (CTAB) protocols on formalin-

DNA yield may differ between taxonomic groups due to factors such blood cell nucleation.

Due to low sample size, we were not able to test if the lack of nucleated red blood cells in mammal tissues impacted DNA yield.

\section{aDNA library preparation methods effectively capture DNA extracted from formalin-}

DNA degradation in museum specimens is a significant challenge to genome sequencing. To improve our conversion of degraded DNA from formalin-preserved tissues into high quality library molecules, we utilized two library preparation methods developed specifically for degraded aDNA templates. We tested the ss2 (46) and dsBEST (47) methods on DNA extracted from both ethanol and formalin-preserved archival tissues. Sequence quality was significantly higher for libraries prepared using the ss2 method compared to the dsBEST protocol. However, this quality difference did not result in significantly lower rates of read alignment or reduced mapped insert length for the dsBEST libraries. While we did not see differences in contamination rates between the two methods, an advantage of the dsBEST method is its reliance on fewer tube transfers and additions of solution, thus reducing opportunities to lose

385 DNA and introduce contaminants. The ss2 and dsBEST methods performed similarly on all 386 twelve of our archival templates, indicating both are well-suited to prepare libraries from DNA 
developed specifically for degraded DNA may prove equally effective. To maximize conversion of fragmented archival DNA template, we advise using a library preparation method designed to capture small fragments whilst minimising contamination risk. Overall, we observed samples with very low DNA yield $(<200 \mathrm{ng}$ from $50 \mathrm{mg}$ of tissue) did not produce

392 libraries with high rates of mapping success. Thus, as a cost-saving measure, we advise quantifying DNA templates prior to library preparation and focussing sequencing effort on higher yielding samples.

\section{High alignment rates of fragmented DNA are achieved through exhaustive match}

397 Removal of adapter sequence and low-quality bases via read-trimming is a standard preprocessing procedure conducted on raw sequencing reads prior to mapping. In the context of libraries prepared from highly degraded templates, filtering and trimming can reduce the dataset substantially. For example, pre-processing of the library prepared from a formalinpreserved Anolis lizard reduced the dataset to $13.5 \%$ of the raw data (40). Although filtering and trimming are effective at removing PCR duplicates and erroneous bases introduced through library preparation and sequencing, quality control parameters should be optimized to avoid removing informative endogenous sequence, particularly with data derived from highly fragmented low-input templates. Compared to DNA extractions from fresh tissue, our extractions from formalin-preserved specimens were highly fragmented as is typical of aDNA sources (55). We opted to trial a computationally efficient approach that eliminates loss of endogenous sequence during pre-processing. The kalign function from the open source kit $4 \mathrm{~b}$ toolkit performs alignments of raw reads by searching for the maximum length match within

410 the read to the reference sequence regardless of the match's position within the read. For each

411 raw read, kalign performs a rapid complete exhaustive match search across the indexed 412 reference genome. The match search is performed recursively through seed expansions 
413 generated along the read length. The longest match to endogenous sequence is retrieved while

414 satisfying the minimum length threshold of the match. Using this approach, we aligned up to

$41521 \%$ and $67 \%$ of raw reads from formalin and ethanol-preserved tissues, respectively. These

416 alignment rates are consistent with the degree of degradation in the DNA we extracted from

417 spirit-preserved museum specimens being intermediate between that of fresh and truly ancient

418 tissues. A previous application of the ss 2 method yielded a maximum of $11.3 \%$ mappable reads

419 from libraries prepared from aDNA tissue sources (25). The same study yielded $60 \%$ and $68 \%$

420 mappable reads from libraries prepared from horse and pig liver stored in buffered formalin for

4215 and 11 years, respectively (25). In comparison, our modest alignment rates may be the result

422 of tissues of intermediate age and using a different metric of calculating the percent of mapped

423 reads.

\section{Sequencing success is strongly influenced by specimen integrity prior to fixation}

425 To explore the effects of formalin-fixation on sequencing success, we selected three specimens

426 preserved with ethanol only and nine specimens preserved with formalin. We found no significant difference in DNA yield between the ethanol and formalin-preserved specimens and

428 the differences we observed in DNA fragment lengths were minimal. Furthermore, we observed equal rates of very poor sequencing success within ethanol and formalin-preserved

430 specimens, indicating preservation method is not a strict determinant of sequencing success.

431 Older, poor-quality ethanol-preserved specimens have previously been shown to be as 432 problematic for genomic analyses as formalin-preserved specimens $(42,56)$. This is not to say 433 preservation method does not impact sequencing success. Two of our ethanol-preserved 434 specimens (P. cinereus and $A$. audax) had much higher mapping rates $(60 \%$ and $67 \%$ reads 435 aligned, respectively) than even our most successful formalin-preserved specimens (R. marina, 436 produced $21 \%$ reads aligned with the HA method). Our findings indicate WGS of formalin437 preserved museum specimens is possible using HA extraction paired with a library preparation 
optimized for conversion of degraded DNA. However, as with all potential DNA sources, the overall integrity of the tissue will ultimately determine sequencing success.

440 The specimens with poor sequencing success $(<1 \%$ reads aligned $)$ were largely older, their 441 preservation media had lower $\mathrm{pH}$ and higher [F] and they were sampled with a tissue other than

442 liver. On the contrary, the specimens with better sequencing success were preserved more 443 recently, their preservation media had neutral $\mathrm{pH}$ and lower [F] and the tissue sampled was 444 liver. We calculated the correlation between specimen quality measures ([F], pH, age and tissue 445 type) and both DNA yield and mapping success. Tissue type was the only quality measure 446 significantly associated with lower DNA yield, with liver yielding significantly more DNA 447 than either muscle or skin. Our higher success with liver is consistent with findings of a 448 previous study comparing sequencing success from liver, muscle and tail-tip in a formalin449 preserved Anolis lizard (40). However, in that study, the tissues were extracted using different 450 methods and thus it could not be determined if success was driven by tissue type or extraction method.

452 Post-mortem DNA degradation occurs more rapidly in liver relative to other bodily tissues 453 including skeletal muscle, heart and brain $(57,58)$. In the museum curatorial setting, specimens 454 undergo varying degrees of post-mortem decay prior to fixation. As is the case for most museum specimens, the length of the post-mortem interval (PMI) was not recorded for the specimens used in this study. Given expected rapid decay of the viscera, we used the visual appearance of the gut contents as a reasonable proxy for the length of the PMI. The four specimens used in this study that lacked liver tissue were visibly more degraded than those with intact liver tissue (Supplementary Figure 2). In the case of the P. cinereus, $P$. carbo and

460 O. anatinus, the complete absence of viscera indicated the internal organs were likely well461 degraded and discarded prior to fixation. For specimens preserved after a long PMI, DNA integrity throughout the carcass would be lower than in specimens preserved after a short PMI. 
463 Therefore, we conclude that the higher yield from specimens sampled with liver is a reflection

464 of overall specimen quality and DNA damage occurring post-mortem but prior to fixation.

\section{Re-thinking formalin damage}

466 Formalin-preserved museum specimens have long been considered intractable sources of 467 gDNA. Encouragingly, we found specimen contact with formaldehyde does not prohibit DNA 468 sequencing if tissue decomposition occurring prior to fixation is minimized. With appropriate 469 sample vetting (Figure 5), HA extraction and DNA library preparation optimized for degraded 470 DNA, historical genomic data may be extracted from many formalin-preserved specimens.

471 These data will not be of similar quality to those recovered from fresh or ethanol-preserved tissues. However, higher sequencing volume and borrowing of analytical methods from the field of aDNA may facilitate reconstruction of historical genomes from formalin-preserved tissues. We found evidence that DNA damage in formalin-preserved specimens shares characteristics with that of aDNA. In addition to capturing shorter fragments with low mapping rates, we observed a pattern of read length periodicity of approximately $10 \mathrm{bp}$. This is consistent with observations in aDNA specimens (59) and is an interval that coincides with the length of a turn of the DNA helix. Pederson et al (2014) attributed the $10 \mathrm{bp}$ read periodicity in specimens greater than 4,000 years old to protection of the DNA by nucleosomes 480 preferentially positioned at $10 \mathrm{bp}$ intervals. We observed a striking periodicity pattern averaging $10.8 \mathrm{bp}$ in HA extracted samples and 10.1bp in the proK-PC samples. The shorter

482 periodicity in the proK treated samples may be due to reduced protection of the ends of DNA 483 fragments by digestion of the nucleosomes during extraction. We did not observe a signal of 484 nucleosome occupancy in read depth or in enrichment of fragments of nucleosome length (147

485 bp) as did Pederson et al., perhaps because we sequenced shorter fragments to comparatively 486 low depth. However, the appearance of $10 \mathrm{bp}$ periodicity suggests it may be possible to infer 
nucleosome occupancy from patterns of DNA degradation observed in formalin-preserved specimens if higher coverage is achieved.

\section{Managing expectations}

490 We have shown WGS of formalin-preserved museum specimens is feasible and success can be improved through specimen quality vetting. We stress; however, measures of specimen quality are imperfect and the key parameters may vary between and within museum collections.

493 Modern collection institutions aim to limit light exposure and temperature variation within their

494 spirit vaults. With older specimens, the likelihood they have been exposed to undocumented

495 DNA-degrading conditions increases. We found the age of the specimen was not strongly predictive of sequencing success, however, we did not sample specimens collected prior to the

497 1960s. This warrants further investigation into the extent to which intact DNA can be extracted 498 from much older formalin-preserved specimens.

499 While preservation media $\mathrm{pH}$ and $[\mathrm{F}]$ were not predictive of sequencing success in our specimens, we note these measures do not always accurately reflect preservation condition. Most institutions periodically top up the specimen jars in their spirit vaults to replace ethanol lost through evaporation. In some cases, the preservation media is replaced entirely. Thus, media $\mathrm{pH}$ and $[\mathrm{F}]$ values at the time of sampling for sequencing may not reflect preservation and long-term storage conditions. With additional sampling of older and more varied specimens, it may be possible to establish clear correlates of sequencing success associated with $\mathrm{pH}$ and $[\mathrm{F}]$.

507 Both researchers and museums would benefit from an improved set of guidelines for strategic 508 decision making based on independent quality metrics rather than qualitative ad hoc assessments. This will empower researchers to most effectively deploy their sequencing

510 budgets and support museums in deciding when to grant requests for destructive sampling. A 
511 cost-benefit analysis should be conducted prior to genomic sequencing of museum specimens.

512 From the perspective of the museum, destructive sampling should be avoided if the specimen

513 is unlikely to yield sufficient DNA to achieve a project's aims. From the perspective of the

514 researcher, sequencing of high-quality specimens should be prioritized to generate high-quality

515 data. To assist in making these assessments, we provide a decision-making tree (Figure 5) for

516 use by both curators and researchers to determine which specimens are likely to be appropriate

517 for genomic analyses.

518 Ultimately, museum curators decide if the potential benefit of sequencing outweighs the

519 damage to the specimen through destructive sampling. Once sampling and DNA extraction has

520 been completed, the decision to proceed with library preparation and sequencing can be made

521 on the basis of DNA yield. We found specimens with high DNA yield $(>1,500 \mathrm{ng} / 50 \mathrm{mg}$

522 tissue) produced a high percentage ( $>20 \%$ ) of mappable reads while specimens with low DNA

523 yield (<200 ng/50 mg tissue) produced virtually no mappable reads. While specimens yielding

524 between $200-1,500 \mathrm{ng}$ of DNA per $50 \mathrm{mg}$ tissue produced relatively low genomic coverage,

525 they did produce high coverage of the mitochondrial genome. Thus, reconstruction of historical

526 mitochondrial haplotypes may be possible from specimens yielding low quantities of DNA.

527 When nuclear data is required, high-volume sequencing should be reserved for high-quality

528 specimens. Generally speaking, most research projects aim to sequence a small number of

529 museum specimens with which to provide a base-line for comparison to contemporary

530 specimens. In light of the limited availability of historical specimens in collections, it is often

531 reasonable and feasible to allocate a relatively large budget to conduct deep sequencing of a

532 small number of specimens. 


\section{Conclusions}

534 Our results demonstrate formalin-fixation is not a complete barrier to WGS in museum

535 specimens. While success is not a guarantee, the use of HA lysis for DNA extraction

536 followed by an appropriate sequencing library preparation optimized for degraded DNA can

537 produce libraries of sufficient complexity for genomic analyses. When selecting specimens

538 for sequencing, our results indicate those with poor gut integrity are least likely to yield

539 sufficient DNA for sequencing.

\section{$540 \quad$ Methods}

\section{Preservation media condition survey}

542 We conducted an unbiased survey of the ANWC spirit vault to measure variation in 543 preservation characteristics that can be sampled without disturbing the specimen. We randomly

544 selected 149 specimen jars spanning a range of taxonomic groups and ages, and removed a 25

$545 \mathrm{~mL}$ aliquot of preservation media. We measured $\mathrm{pH}$ using an Orion ${ }^{\mathrm{TM}}$ Versa Star Pro ${ }^{\mathrm{TM}}$

546 benchtop pH meter (Thermo Scientific) and [F] using MQuant ${ }^{\circledR}$ test strips (Merck). Where [F]

547 was at the upper detection limit of the test strips, we diluted the aliquot 1:10 with ultrapure 548 water and remeasured, extrapolating the neat concentration of the media by multiplying the 549 measurement by the dilution factor.

\section{Specimen selection}

551 To select specimens for genomic sequencing, we first identified those with a publicly available

552 whole-genome reference for the specimen species or closely related species. Of these

553 specimens, we selected 12 representing a range of taxonomic groups, preservation conditions

554 and ages and sampled $50 \mathrm{mg}$ of tissue. We sampled liver tissue when it was available. Muscle

555 was sampled from an ethanol-preserved $P$. cinereus specimen and from formalin-preserved $T$.

556 guttata and O. anatinus specimens. Skin was sampled from an ethanol-preserved P. carbo. All 
specimens sampled with liver were preserved as whole animals whereas substantial portions of the body were absent from those specimens sampled with muscle or skin (Supplementary Figure 2). From the nine formalin-preserved specimens, we selected three with which to test

560 the relative success of three DNA extraction methods. To represent "good" quality formalin-

561 preserved specimens, we selected a cane toad (R. marina) preserved in 2002. Visually, this specimen appeared minimally degraded and measurements of the storage media indicated low

$563[\mathrm{~F}]$ and a neutral $\mathrm{pH}$. To represent "poor" quality formalin-preserved specimens, we selected a tammar wallaby (M. eugenii) preserved in 1989 and a saltwater crocodile (C. porosus) preserved in 1973. Visually, these two "poor" specimens were reasonably well-preserved, however, measurements of the storage media indicated substantial $[\mathrm{F}]$ in both specimen jars and mildly acidic $\mathrm{pH}$ in that of the wallaby.

\section{Tissue preparation}

569 Prior to DNA extraction, we liquid nitrogen pulverized all dissected tissue into a fine powder using a cryoPREP ${ }^{\circledR}\left(\right.$ Covaris) dry pulverizer (three impacts to a TT05 tissueTUBE ${ }^{\mathrm{TM}}$ on intensity setting three; $10 \mathrm{sec}$ in liquid nitrogen between impacts). We then stored the pulverized tissue powder in $70 \%$ ethanol at $-80^{\circ} \mathrm{C}$ until further processing. We re-hydrated the pulverized tissue by stepping it into 50\% ethanol, 30\% ethanol then TE buffer with rocking for 10 min intervals. For the nine formalin-fixed tissues, we quenched excess formaldehyde by rocking for $2 \mathrm{hrs}$ in $1 \mathrm{~mL}$ GTE buffer (100 mM glycine, $10 \mathrm{mM}$ Tris-HCL, $\mathrm{pH}$ 8.0, $1 \mathrm{mM}$ EDTA), followed by a further wash in fresh GTE for $2 \mathrm{hrs}$ and a final fresh GTE wash overnight at room temperature. We removed the GTE buffer and washed with rocking in sterile water for $10 \mathrm{~min}$.

\section{Proteinase K DNA extraction}

580 We conducted two variations on a standard proteinase K (proK) digestion. For each specimen, 581 we digested two $50 \mathrm{mg}$ (wet weight) aliquots of tissue overnight at $55^{\circ} \mathrm{C}$ with $30 \mu \mathrm{L}$ of 20 
$\mathrm{mg} / \mathrm{mL}$ proteinase $\mathrm{K}$ in $970 \mu \mathrm{L}$ lysis buffer $(10 \mathrm{mM} \mathrm{NaCl}, 20 \mathrm{mM}$ Tris- $\mathrm{HCl}, \mathrm{pH} 8.0,1 \mathrm{mM}$

$\mu \mathrm{L}$ TE, or (B) a QIAquick PCR purification column (Qiagen) (proK-col), following the manufacturer's instructions and eluting the DNA in $30 \mu \mathrm{L}$ TE. Alongside the museum tissues, we processed tissue-free controls. We quantified extracted dsDNA using a Qubit fluorometer and high sensitivity (HS) DNA kit (Invitrogen).

\section{Hot alkaline lysis DNA extraction}

590 For the hot alkaline lysis (HA) extractions, we heated $50 \mathrm{mg}$ (wet weight) tissue aliquots to $120^{\circ} \mathrm{C}$ for $25 \mathrm{~min}$ in $500 \mu \mathrm{L}$ of alkali buffer $(0.1 \mathrm{M} \mathrm{NaOH}$ with $1 \% \mathrm{SDS}, \mathrm{pH} 13)$ according to methods described in (52). We purified DNA from the lysate with three phenol-chloroform a Qubit fluorometer and HS DNA kit.

\section{Library preparation methods}

597 To avoid cross-contamination, we prepared all sequencing libraries in the Ecogenomics and

598 Bioinformatics Laboratory trace facility at the Australian National University following 599 standard anti-contamination procedures. We prepared libraries from all DNA extracts and 600 tissue-free controls using two methods developed for high efficiency conversion of fragmented 601 aDNA; the single-stranded method v2.0 (ss2) (25) and the BEST double-stranded method 602 (dsBEST) (26). Concurrently, we prepared DNA-free control libraries. For sequencing of Read 6031 in both library preparation methods, we used an adapter with the sequence 5 604 AGATCGGAAGAGCACACGTCTGAACTCCAGTCAC-3`. For sequencing of Read 2, we 605 used adapters with the sequences 5`-GGAAGAGCGTCGTGTAGGGAAAGAGTGT-3`and 606 5-AGATCGGAAGAGCGTCGTGTAGGGAAAGAGTGT-3` for the ss2 and dsBEST 
methods, respectively. We removed excess adapter and primer dimer by isolating fragments

608 between $160 \mathrm{bp}$ and $400 \mathrm{bp}$ from the resulting libraries using the PippinHT size-selection

609 system (Sage Science). We further purified the libraries with a MinElute PCR purification kit

610 (Qiagen) and quantitated the library concentrations using the LabChip GXII (PerkinElmer)

611 capillary electrophoresis system. We then pooled the libraries in approximately equimolar

612 concentrations and measured the concentration of the final pooled library using a Qubit

613 fluorometer and HS DNA kit. The Australian Genome Research Facility sequenced the pooled

614 library on a 150 bp paired-end S4 flow cell on the Illumina NovaSeq 6000 platform.

\section{Quality control of raw reads}

616 We computed quality control metrics for the raw reads using FastQC v.0.11.8 (60). Our adapter

617 content analysis included both default Illumina adapters and our custom library adapters. To

618 rapidly detect library contamination by non-target species' DNA, we classified the taxonomic

619 origin of reads using Kraken2 v.2.0.9b (61). We estimated the number of unique fragments 620 present in the raw sequence libraries with the EstimateLibraryComplexity function of PICARD $621 \quad$ v.2.9.2(62).

\section{Alignment}

623 We aligned reads to reference nuclear and mitochondrial genomes obtained from the DNA Zoo

624 Consortium $(63,64)$ and GenBank (65) (Supplementary Table 1). Species-specific reference 625 genomes were not available for three of the specimens. For $A$. audax, F. cenchroides and $P$. 626 minima, we used the reference genomes of species in the same genera- $A$. chrysaetos, $F$. 627 perigrinus and $P$. vitticeps, respectively (Supplementary Table 1). We hard-masked the eleven 628 genomes with RepeatMasker v.4.1.0 (66) including our ss2 and dsBEST library adapters in the 629 repeat database and applying the -qq option allowing $10 \%$ less sensitivity while decreasing 630 processing time. We aligned raw reads with the kalign function of the ngskit4b tool suite 631 v.200218 (67) with options -c25 (--minchimeric=<int>; minimum chimeric length as a 
632 percentage of probe length) -125 (--minacceptreadlen=<int $>$; after any end trimming only

633 accept read for further processing if read is at least this length) $-\mathrm{d} 50$ (--pairminlen=<int $>$;

634 accept paired end alignments with observed insert sizes of at least this) $-\mathrm{U} 4$ (--pemode=<int $>$;

635 paired end processing mode: 4 - paired end no orphan recovery treating orphan ends as SE).

636 We removed PCR and optical duplicates from the alignments using the MarkDuplicates

637 function of PICARD enabling REMOVE_DUPLICATES=TRUE. For each de-duplicated

638 alignment, we computed a histogram of aligned insert lengths and calculated the mean aligned

639 insert length using the CollectInsertSizeMetrics function of PICARD.

\section{Genome coverage analyses}

641 We estimated nuclear genome coverage $\left(C_{n u c}\right)$ as the number of unique aligned reads multiplied

642 by the mean insert length divided by unmasked genome size. To estimate how much genomic 643 coverage could be achieved by increasing sequencing depth, we calculated the sequenced 644 proportion of the prepared library as the number of read pairs examined divided by the 645 estimated library size. We estimated the number of possible reads represented in the prepared 646 library by dividing the number of actual reads aligned by the sequenced proportion of the

647 library. We then roughly estimated the potential genomic coverage represented in the full 648 prepared library $\left(\mathrm{C}_{\mathrm{pot}}\right)$ as: $\quad(\#$ possible reads $\times$ mean insert length $($ bp $)) \div$ 649 genome size $(b p)$. To calculate the proportion of mitochondrial genome sites with $30 \mathrm{X}$ or 650 greater coverage $\left(\mathrm{C}_{\mathrm{mt}}\right)$, we executed the Samtools depth function (68) on SAM files for the mitochondrial contigs for each species combined across all libraries.

\section{Statistical analyses}

653 We performed statistical analyses in the R environment, v.4.0.2 (69) and produced figures using the packages ggplot2 (70) and ggpubr (71). To test if the residuals of data were normally distributed, we ran Shapiro-Wilk tests with the function shapiro.test. We conducted T-tests 
bioRxiv preprint doi: https://doi.org/10.1101/2021.04.18.440380; this version posted April 20, 2021. The copyright holder for this preprint

(which was not certified by peer review) is the author/funder, who has granted bioRxiv a license to display the preprint in perpetuity. It is made available under aCC-BY-NC 4.0 International license.

657 confidence intervals using Tukey’s Honest Significant Difference method (Tukey test) with the

658 function TukeyHSD in the base package stats. We computed Pearson correlation coefficients

659 with associated p-values with the ggpubr function stat_cor. 


\section{$660 \quad$ Figures}

\section{Figure 1. Preservation media survey results of formalin-fixed specimens in the}

\section{Australian National Wildlife Collection}

663 Residual formaldehyde concentration [F] (mg/L) is shown on a log-scale in relation to $\mathrm{pH}$.

664 Individual specimens $(\mathrm{N}=65)$ are colored by the time since their collection (age) and the

665 specimens selected for sequencing are indicated by species name. A linear model was used to

666 fit a regression line and standard error is shown in grey; $\mathrm{R}=$ Pearson's correlation coefficient.

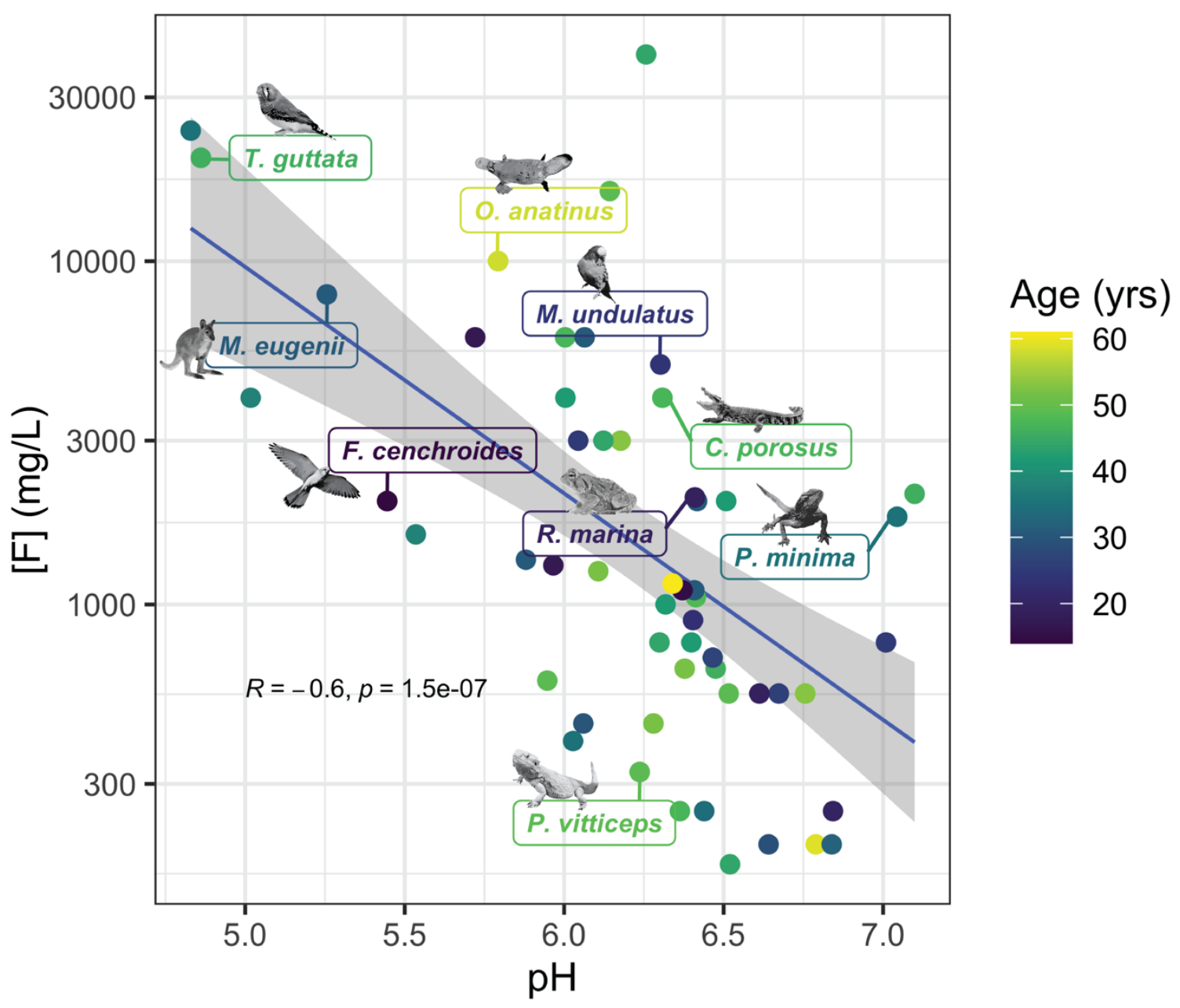


bioRxiv preprint doi: https://doi.org/10.1101/2021.04.18.440380; this version posted April 20, 2021. The copyright holder for this preprint

(which was not certified by peer review) is the author/funder, who has granted bioRxiv a license to display the preprint in perpetuity. It is made available under aCC-BY-NC 4.0 International license.

669 Figure 2. Effectiveness of extraction and library preparation methods for $R$. marina, $C$.

$670 \quad$ porosus and $M$. eugenii specimens.

671 (A) Alignment to the whole genome expressed as the percentage of reads aligning (B)

672 Alignment to the mitochondrial genome expressed as the number of reads aligned per million

673 raw reads $(\mathrm{MRM})$. dsBEST $=$ BEST double-stranded method (26); ss2 = single-stranded

674 method v2.0 (25); HA = hot alkaline lysis; proK-col = proteinase $\mathrm{K}$ digestion followed by

675 column purification; proK-PC = proteinase $\mathrm{K}$ digestion followed by phenol-chloroform

676 extraction.
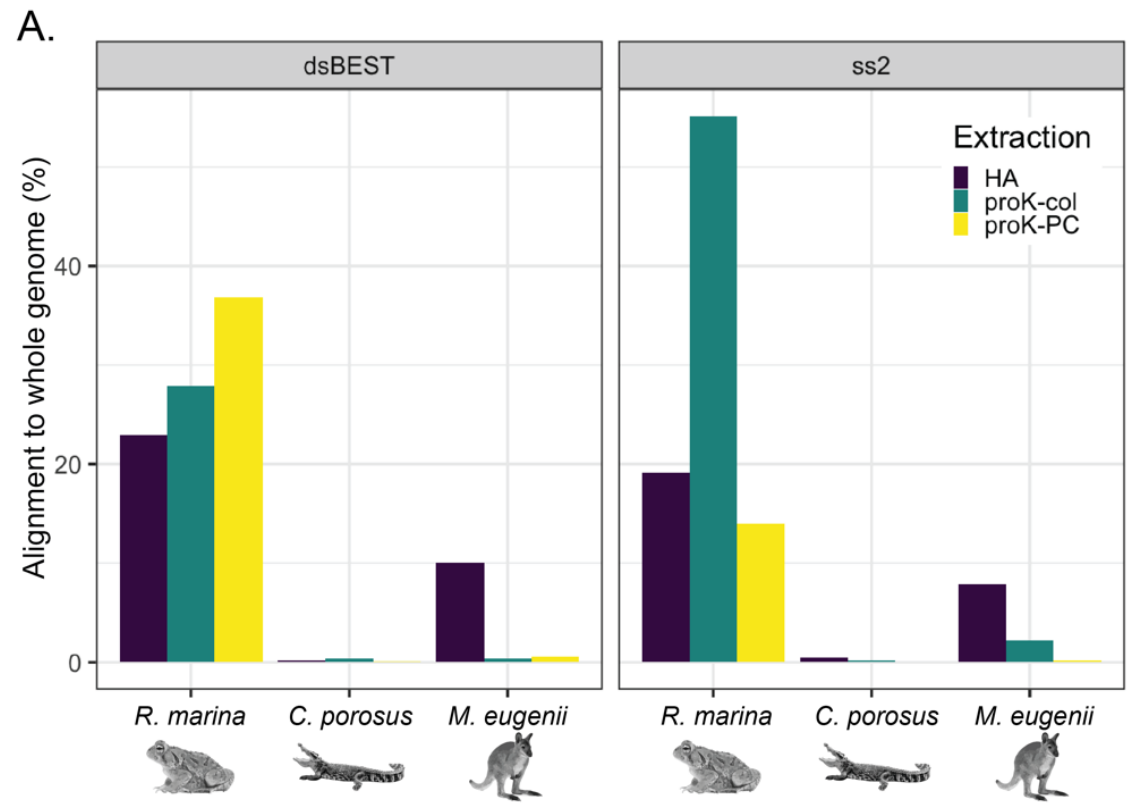

B.
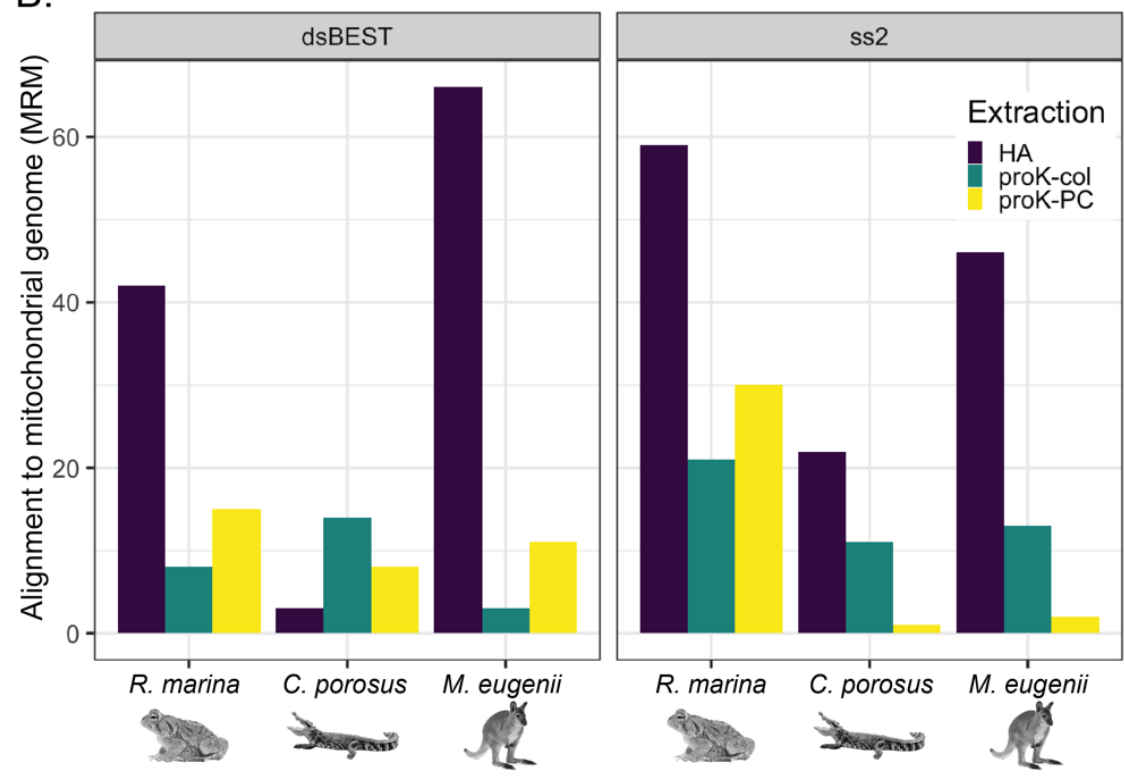
bioRxiv preprint doi: https://doi.org/10.1101/2021.04.18.440380; this version posted April 20, 2021. The copyright holder for this preprint

(which was not certified by peer review) is the author/funder, who has granted bioRxiv a license to display the preprint in perpetuity. It is made available under aCC-BY-NC 4.0 International license.

Figure 3. Alignment results for hot alkali extracted samples

679 The correlation between the percentage of reads aligned to the whole genome (combining

680 both library preparations of the hot alkali extracted specimens) and (A) preservation media

$681 \mathrm{pH},(\mathrm{B})$ preservation media formaldehyde concentration $(\mathrm{g} / \mathrm{L}),(\mathrm{C})$ number of years in the

682 collection and (D) tissue sampled. In A-C, all specimens are shown colored by their fixation

683 type and $\mathrm{R}=$ Pearson's correlation coefficient for the formalin-fixed specimens. In D, only

684 the formalin-preserved specimens are plotted and individual specimens are shown with black

685 dots, $*=p<0.05$.

A.

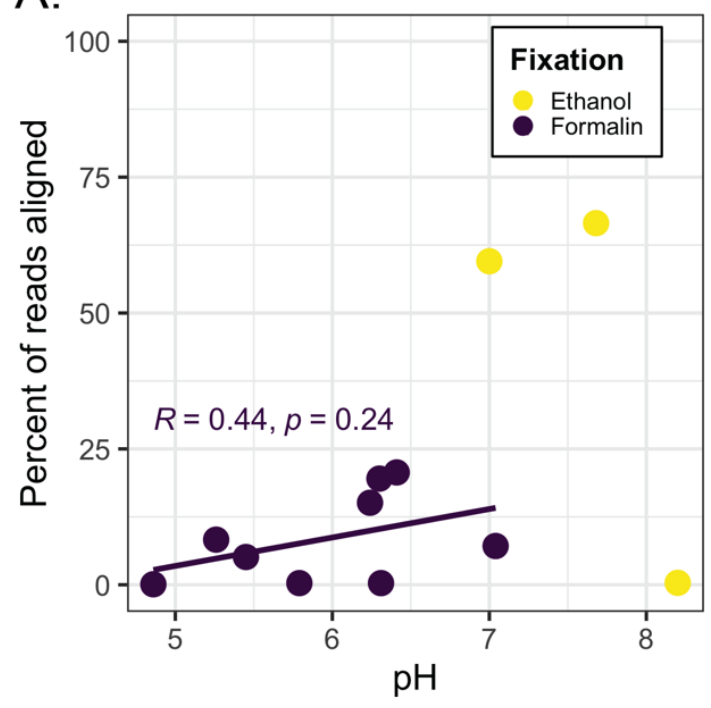

C.

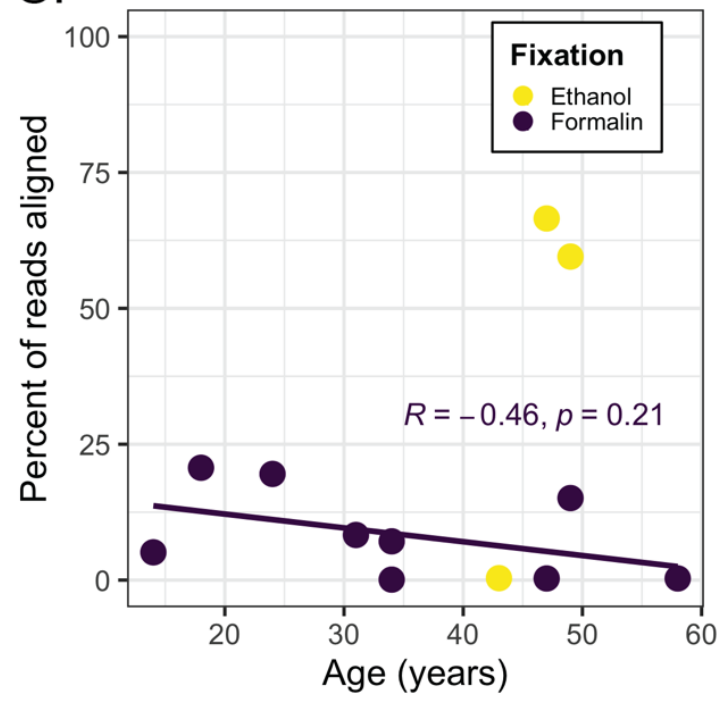

B.

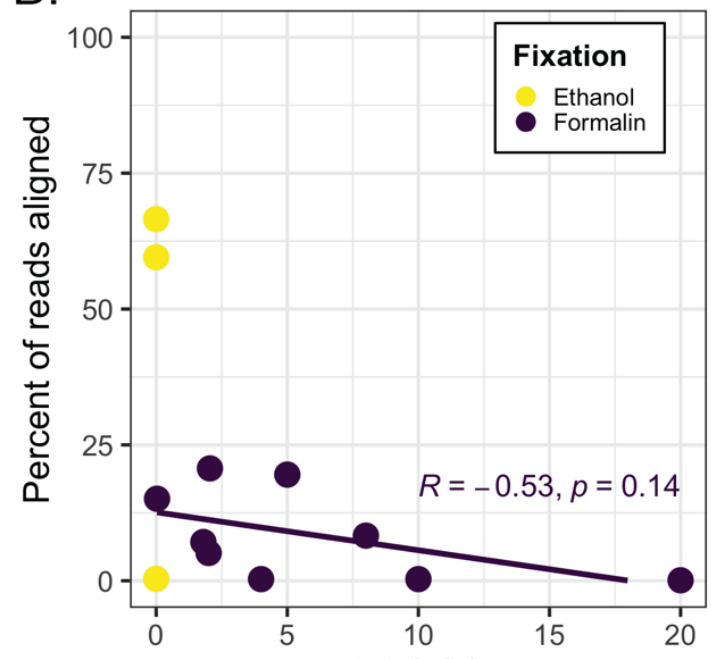

$[\mathrm{F}](\mathrm{g} / \mathrm{L})$

D.

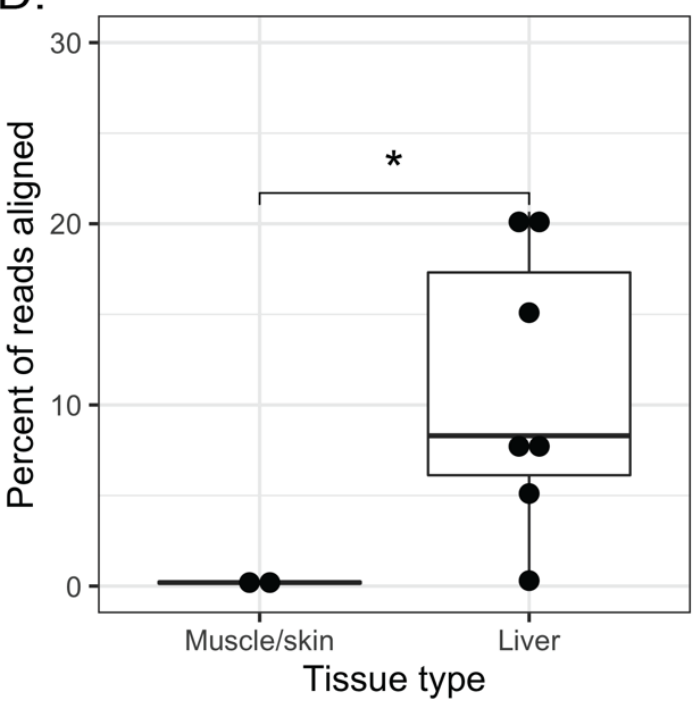


bioRxiv preprint doi: https://doi.org/10.1101/2021.04.18.440380; this version posted April 20, 2021. The copyright holder for this preprint

(which was not certified by peer review) is the author/funder, who has granted bioRxiv a license to display the preprint in perpetuity. It is made available under aCC-BY-NC 4.0 International license.

\section{Figure 4. Libraries with read periodicity}

688 The frequency of insert lengths, in bp, estimated from the mapped dsBEST libraries is shown

689 for six preserved specimens. Read periodicity in the $R$. marina libraries from the proteinase K

690 with phenol-chloroform (proK-PC) extractions averages $10.1 \mathrm{bp}$ while periodicity in libraries

691 from the hot alkali extractions of six specimens averages $10.8 \mathrm{bp}$.

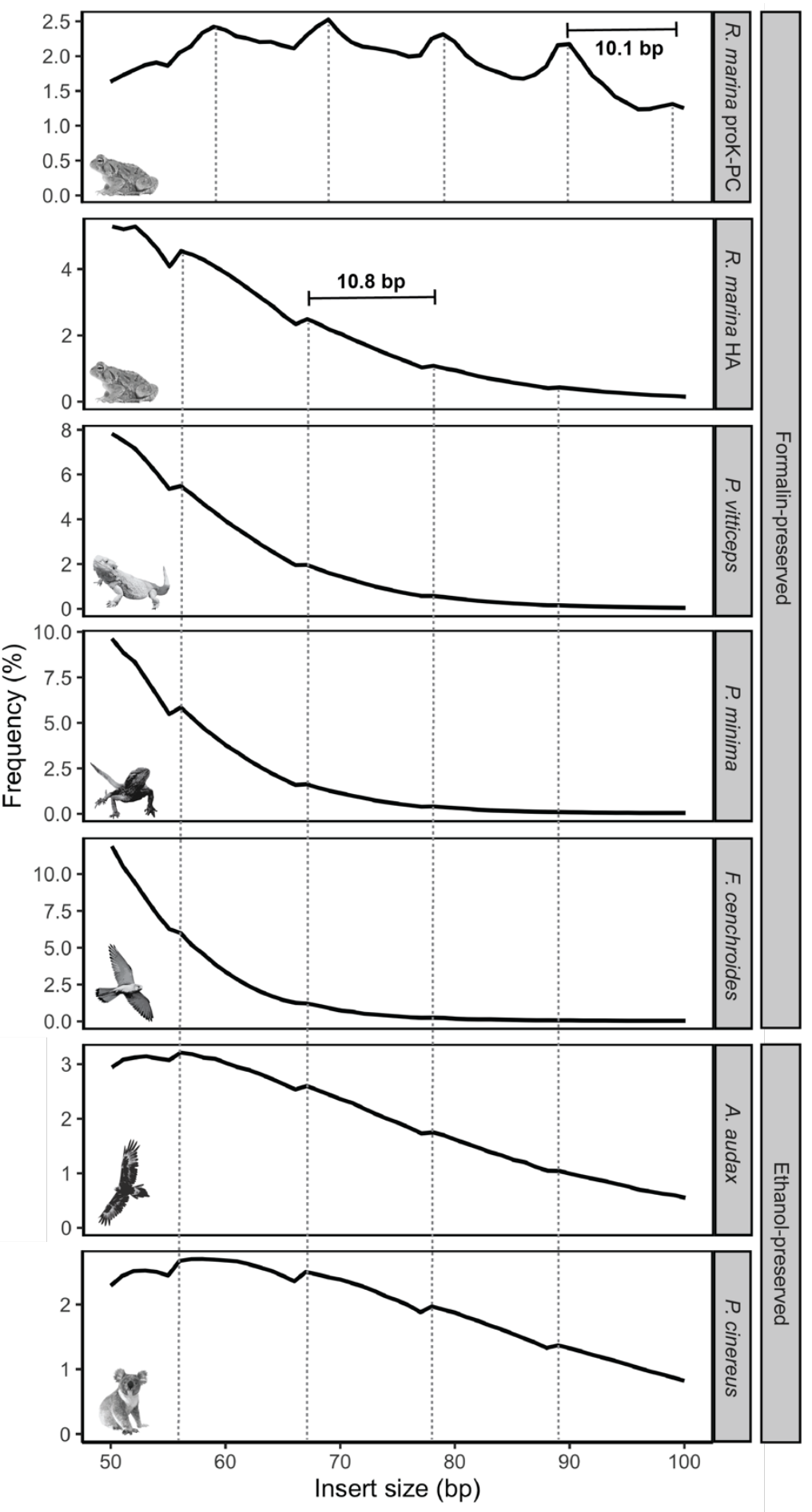


bioRxiv preprint doi: https://doi.org/10.1101/2021.04.18.440380; this version posted April 20, 2021. The copyright holder for this preprint

(which was not certified by peer review) is the author/funder, who has granted bioRxiv a license to display the preprint in perpetuity. It is made available under aCC-BY-NC 4.0 International license.

693 Figure 5. Decision-making tree for a priori estimation of likely sequencing success in

694 spirit-preserved museum specimens.

695 Green ticks indicate the specimen is well-suited the sequencing application and there is a high

696 likelihood of success. Black question marks indicate the specimen is marginal for the

697 sequencing application and there is high variation in the likelihood of success. Red crosses

698 indicate the specimen is not well-suited for the sequencing application and there is a low

699 likelihood of success.

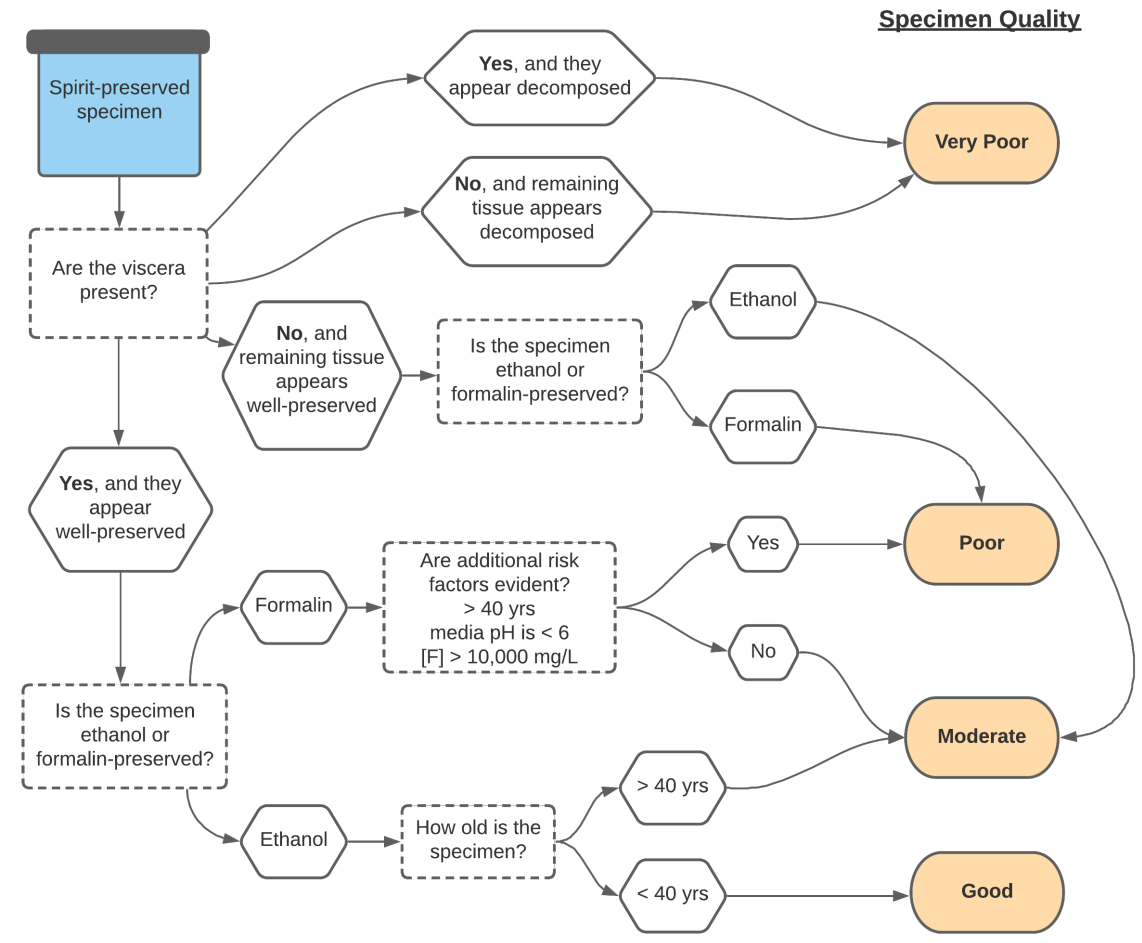

Specimen quality

\begin{tabular}{|c|c|c|c|c|}
\hline & Good & Moderate & Poor & Very Poor \\
\hline $\begin{array}{l}\text { Amplicon } \\
\text { sequencing }\end{array}$ & & & & \\
\hline $\begin{array}{l}\text { Capture-based } \\
\text { genotyping }\end{array}$ & & & & \\
\hline $\begin{array}{c}\text { Whole } \\
\text { mitochondrial } \\
\text { sequencing }\end{array}$ & & & & \\
\hline $\begin{array}{l}\text { Whole genome } \\
\text { sequencing }\end{array}$ & & & & \\
\hline
\end{tabular}




\section{Declarations}

702 Ethics approval and consent to participate

703 Not applicable.

\section{Consent for publication}

705 Not applicable.

\section{Availability of data and materials}

707 The sequencing data generated and analysed in this study are archived in the CSIRO Data

708 Access Portal. Correspondence and requests for materials should be addressed to CEH

709 (clare.holleley@csiro.au)

\section{Competing interests}

711 The authors declare they have no competing interests.

\section{$712 \quad$ Funding}

713 Funding for this study was provided by the Environomics CSIRO Future Science Platform

714 (grants R-10011 and R-14486) awarded to CEH.

\section{Authors' contributions}

716 This study was conceived by CEH. Experiments were designed by CEH, MRA and AG and

717 conducted by MRA and AG. Data analysis was conducted by EEH, JS, MRA and AG and

718 advised by DMG and CEH. All authors contributed to the writing and editing of the manuscript.

\section{Acknowledgements}

720 We thank Olly Berry and Andrew Young for their leadership within the Environomics Future

721 Science Platform. We thank the director of the Australian National Wildlife Collection, Leo

722 Joseph, and the ANWC staff (specifically, Margaret Cawsey, Alex Drew, Tonya Haff, Dave

723 Spratt and Chris Wilson) for their contributions of curatorial expertise, metadata management

724 and sampling assistance. We thank Kerensa McElroy for her assistance and guidance in data 
management. We thank Ondrej Hlinka and CSIRO IM\&T Client Services for their assistance

726 in utilising the CSIRO Pearcey supercomputing system. We thank Niccy Aitkin for her

727 guidance in utilising the Australian National University's Ecogenomics and Bioinformatics

728 Laboratory for library preparation. We thank the Australian Genome Research Facility for their

729 conversations around sequencing. We thank Sharon Appleyard, Meghan Castelli, Andrew

730 George, Peter Grewe, Michael Hope, Safia Maher, Annette McGrath, Corinna Paeper, Cheng

731 Soon-Ong, Andrew Spriggs, Jen Taylor and Christfried Webers for their valuable comments

732 on the study design and implementation. We would like to acknowledge the contribution of

733 Bioplatforms Australia in the generation of data used in this publication. Bioplatforms

734 Australia is enabled by NCRIS. 


\section{References}

736

737

738

739

740

741

742

743

744

745

746

747

748

749

750

751

752

753

754

755

756

757

758

759

760

761

762

763

764

765

766

767

768

769

770

771

772

1. Shaffer HB, Fisher RN, Davidson C. The role of natural history collections in documenting species declines. Trends Ecol Evol. 1998;13(1):27-30.

2. Meineke EK, Davies TJ, Daru BH, Davis CC. Biological collections for understanding biodiversity in the Anthropocene. Philos Trans R Soc Lond B Biol Sci. 2018; doi:10.1098/rstb.2017.0386

3. Holmes MW, Hammond TT, Wogan GOU, Walsh RE, LaBarbera K, Wommack EA, Martins FM, Crawford JC, Mack KL, Bloch LM, Nachman MW. Natural history collections as windows on evolutionary processes. Mol Ecol. 2016;25(4):864-81.

4. Martínková N, Searle JB. Amplification success rate of DNA from museum skin collections: a case study of stoats from 18 museums. Mol Ecol Notes. 2006;6(4):1014-7.

5. Rawlence NJ, Wood JR, Armstrong KN, Cooper A. DNA content and distribution in ancient feathers and potential to reconstruct the plumage of extinct avian taxa. Proc Biol Sci. 2009;276(1672):3395-402.

6. Sefc KM, Payne RB, Sorenson MD. Microsatellite amplification from museum feather samples: effects of fragment size and template concentration on genotyping errors. Auk. 2003;120(4):982-9.

7. Grealy A, Bunce M, Holleley CE. Avian mitochondrial genomes retrieved from museum eggshell. Mol Ecol Resour. 2019;19(4):1052-62.

8. Grealy A, Langmore NE, Joseph L, Holleley CE. Genetic barcoding of museum eggshell improves data integrity of avian biological collections. Sci Rep. 2021;11(1):1605.

9. Tsai WLE, Schedl ME, Maley JM, McCormack JE. More than skin and bones: comparing extraction methods and alternative sources of DNA from avian museum specimens. Mol Ecol Resour. 2020;20(5):1220-7.

10. McElroy K, Beattie K, Symonds MRE, Joseph L. Mitogenomic and nuclear diversity in the Mulga Parrot of the Australian arid zone: cryptic subspecies and tests for selection. Emu - Austral Ornithology. 2018;118(1):22-35.

11. Morgan CC, Creevey CJ, O'Connell MJ. Mitochondrial data are not suitable for resolving placental mammal phylogeny. Mamm Genome. 2014;25(11-12):636-47.

12. Hackett SJ, Kimball RT, Reddy S, Bowie RCK, Braun EL, Braun MJ, et al. A phylogenomic study of birds reveals their evolutionary history. Science. 2008;320(5884):1763-8.

13. Derkarabetian S, Benavides LR. Sequence capture phylogenomics of historical ethanolpreserved museum specimens: unlocking the rest of the vault. Mol Ecol. 2019; doi: 10.1111/1755-0998.13072.

14. Linck EB, Hanna ZR, Sellas A, Dumbacher JP. Evaluating hybridization capture with RAD probes as a tool for museum genomics with historical bird specimens. Ecol Evol. 2017;7(13):4755-67. 
15. Wood HM, González VL, Lloyd M, Coddington J, Scharff N. Next-generation museum genomics: phylogenetic relationships among palpimanoid spiders using sequence capture techniques (Araneae: Palpimanoidea). Mol Phylogenet Evol. 2018;127:907-18.

16. Parejo M, Wragg D, Henriques D, Charrière J-D, Estonba A. Digging into the genomic past of Swiss honey bees by whole-genome sequencing museum specimens. Genome Biol Evol. 2020;12(12):2535-51.

17. Staats M, Erkens RHJ, van de Vossenberg B, Wieringa JJ, Kraaijeveld K, Stielow B, Geml J, Richardson JE, Bakker FT. Genomic treasure troves: complete genome sequencing of herbarium and insect museum specimens. PLoS One. 2013;8(7):e69189.

18. Feigin CY, Newton AH, Doronina L, Schmitz J, Hipsley CA, Mitchell KJ, Gower G, Llamas B, Soubrier J, Heider TN, Menzies BR, Cooper A, O’Neill RJ, Pask AJ. Genome of the Tasmanian tiger provides insights into the evolution and demography of an extinct marsupial carnivore. Nat Ecol Evol. 2018;2(1):182-92.

19. Atlas of Living Australia. https://www.ala.org.au/. Accessed 28 January 2021.

20. Appleyard SA, Maher S, Pogonoski JP, Bent SJ, Chua X-Y, McGrath A. Assessing DNA for fish identifications from reference collections: the good, bad and ugly shed light on formalin fixation and sequencing approaches. J Fish Biol. 2021; doi:10.1111/jfb.14687.

21. Srinivasan M, Sedmak D, Jewell S. Effect of fixatives and tissue processing on the content and integrity of nucleic acids. Am J Pathol. 2002;161(6):1961-71.

22. Williams C, Ponten F, Moberg C, Soderkvist P, Uhlen M, Ponten J, Sitbon G, Lundeberg J. A high frequency of sequence alterations is due to formalin fixation of archival specimens. Am J Pathol. 1999;155(5):1467-71.

23. Do H, Dobrovic A. Sequence artifacts in DNA from formalin-fixed tissues: causes and strategies for minimization. Clin Chem. 2015;61(1):64-71.

24. Burrell AS, Disotell TR, Bergey CM. The use of museum specimens with high-throughput DNA sequencers. J Hum Evol. 2015;79:35-44.

25. Gansauge M-T, Gerber T, Glocke I, Korlevic P, Lippik L, Nagel S, Riehl LM, Schmidt A, Meyer M. Single-stranded DNA library preparation from highly degraded DNA using T4 DNA ligase. Nucleic Acids Res. 2017;45(10):e79.

26. Carøe C, Gopalakrishnan S, Vinner L, Mak SST, Sinding MHS, Samaniego JA, Wales N, Sicheritz-Pontén, Gilbert MTP. Single-tube library preparation for degraded DNA. Methods in Ecology and Evolution. 2018;9(2):410-419.

27. Parks M, Lambert D. Impacts of low coverage depths and post-mortem DNA damage on variant calling: a simulation study. BMC Genomics. 2015;16:19.

28. Robbe P, Popitsch N, Knight SJL, Antoniou P, Becq J, He M, et al. Clinical whole-genome sequencing from routine formalin-fixed, paraffin-embedded specimens: pilot study for the 100,000 Genomes Project. Genet Med. 2018; doi:10.1038/gim.2017.241.

29. Simmons JE. Fluid preservation : a comprehensive reference. Lanham: Rowman \& Littlefield; 2014. 
30. MacLeod ID. Washing formaldehyde from fixed spirit specimens: a mechanism for the preservation of Megamouth III. AICCM Bulletin. 2008;31(1):36-43.

31. Koshiba M, Ogawa K, Hamazaki S, Sugiyama T, Ogawa O, Kitajima T. The effect of formalin fixation on DNA and the extraction of high-molecular-weight DNA from fixed and embedded tissues. Pathol Res Pract. 1993;189(1):66-72.

32. Bär W, Kratzer A, Mächler M, Schmid W. Postmortem stability of DNA. Forensic Sci Int. 1988;39(1):59-70.

33. Palmer ADN. DNA isolation and amplification from formaldehyde-fixed animal tissues rich in mucopolysaccharides, pigments, and chitin. Prep Biochem Biotechnol. 2009;39(1):72-80.

34. Bibi SS, Rehman A, Minhas RA, Janjua S. Evaluation of DNA extraction method from formalin preserved skin samples of Panthera pardus for molecular genetic assessment. The Journal of Animal \& Plant Sciences. 2015;25:1196-9.

35. Lutterschmidt WI, Cureton JC Ii, Gaillard AR. "Quick" DNA extraction from claw clippings of fresh and formalin-fixed box turtle (Terrapene ornata) specimens. Herpetol Rev. 2010;41(3):313-5.

36. Scatena MP, Morielle-Versute E. Suitability of DNA extracted from archival specimens of fruit-eating bats of the genus Artibeus (Chiroptera, Phyllostomidae) for polymerase chain reaction and sequencing analysis. Genet Mol Biol. 2008;31(1):160-5.

37. Joshi BD, Mishra S, Singh SK, Goyal SP. An effective method for extraction and polymerase chain reaction (PCR) amplification of DNA from formalin preserved tissue samples of snow leopard. Afr J Biotechnol. 2013;12(22):3399-404.

38. Shedlock AM, Haygood MG, Pietsch TW, Bentzen P. Enhanced DNA extraction and PCR amplification of mitochondrial genes from formalin-fixed museum specimens. Biotechniques. 1997;22(3):394-400.

39. Boyle EE, Zardus JD, Chase MR, Etter RJ, Rex MA. Strategies for molecular genetic studies of preserved deep-sea macrofauna. Deep Sea Res Part I. 2004;51(10):1319-36.

40. Hykin SM, Bi K, McGuire JA. Fixing formalin: a method to recover genomic-scale DNA sequence data from formalin-fixed museum specimens using high-throughput sequencing. PLoS One. 2015;10(10):e0141579.

41. Gould AL, Fritts-Penniman A, Gaisiner A. Museum genomics illuminate the high specificity of a bioluminescent symbiosis across a genus of reef fish. Front Ecol Evol. 2021; doi:10.3389/fevo.2021.630207.

42. Ruane S, Austin CC. Phylogenomics using formalin-fixed and 100+ year-old intractable natural history specimens. Mol Ecol Resour. 2017;17(5):1003-8.

43. Kehlmaier C, Zinenko O, Fritz U. The enigmatic Crimean green lizard (Lacerta viridis magnifica) is extinct but not valid: mitogenomics of a 120 -year-old museum specimen reveals historical introduction. J Zoolog Syst Evol Res. 2020;58(1)303-7. 
850

44. Diaz-Viloria N, Sanchez-Velasco L, Perez-Enriquez R. Inhibition of DNA amplification in marine fish larvae preserved in formalin. J Plankton Res. 2005;27(8):787-92.

45. Pierson TW, Kieran TJ, Clause AG, Castleberry NL. Preservation-induced morphological change in salamanders and failed DNA extraction from a decades-old museum specimen: implications for Plethodon ainsworthi. J Herpetol. 2020;54(2):137-43.

46. McGaughran A. Effects of sample age on data quality from targeted sequencing of museum specimens: what are we capturing in time? BMC Genomics. 2020;21(1):188.

47. Watanabe M, Hashida S, Yamamoto H, Matsubara T, Ohtsuka T, Suzawa K, Maki Y, Soh J, Asano H, Tsukuda K, Toyooka S, Miyoshi S. Estimation of age-related DNA degradation from formalin-fixed and paraffin-embedded tissue according to the extraction methods. Exp Ther Med. 2017;14(3):2683-8.

48. Zimmermann J, Hajibabaei M, Blackburn DC, Hanken J, Cantin E, Posfai J, Evans TC. DNA damage in preserved specimens and tissue samples: a molecular assessment. Front Zool. 2008;5:18.

49. Freedman J, van Dorp LB, Brace S. Destructive sampling natural science collections: an overview for museum professionals and researchers. Journal of Natural Science Collections. 2018;5:21-34.

50. Shi S-R, Datar R, Liu C, Wu L, Zhang Z, Cote RJ, Taylor CR. DNA extraction from archival formalin-fixed, paraffin-embedded tissues: heat-induced retrieval in alkaline solution. Histochem Cell Biol. 2004;122(3):211-8.

51. Shi S-R, Cote RJ, Wu L, Liu C, Datar R, Shi Y, Liu D, Lim H, Taylor CR. DNA extraction from archival formalin-fixed, paraffin-embedded tissue sections based on the antigen retrieval principle: heating under the influence of $\mathrm{pH}$. J Histochem Cytochem. 2002;50(8):1005-11.

52. Campos PF, Gilbert TMP. DNA extraction from formalin-fixed material. Ancient DNA: Methods and Protocols. 2012;840:81-5.

53. Splendiani A, Fioravanti T, Giovannotti M, Olivieri L, Ruggeri P, Nisi Cerioni P, Vanni $\mathrm{S}$, Enrichetti F, Caputo Barucchi V. Museum samples could help to reconstruct the original distribution of Salmo trutta complex in Italy. J Fish Biol. 2017;90(6):2443-51.

54. Paireder S, Werner B, Bailer J, Werther W, Schmid E, Patzak B, Cichna-Markl M. Comparison of protocols for DNA extraction from long-term preserved formalin fixed tissues. Anal Biochem. 2013;439(2):152-60.

55. Prüfer K, Stenzel U, Hofreiter M, Pääbo S, Kelso J, Green RE. Computational challenges in the analysis of ancient DNA. Genome Biol. 2010;11(5):R47.

56. McGuire JA, Cotoras DD, O'Connell B, Lawalata SZS, Wang-Claypool CY, Stubbs A, Huang X, Wogan GOU, Hykin SM, Reilly SB, Bi K, Riyanto A, Arida E, Smith LL, Milne $\mathrm{H}$, Streicher JW, Iskandar DT. Squeezing water from a stone: high-throughput sequencing from a 145-year old holotype resolves (barely) a cryptic species problem in flying lizards. PeerJ. 2018;6:e4470. 
57. Johnson LA, Ferris JAJ. Analysis of postmortem DNA degradation by single-cell gel electrophoresis. Forensic Sci Int. 2002;126(1):43-7.

58. Itani M, Yamamoto Y, Doi Y, Miyaishi S. Quantitative analysis of DNA degradation in the dead body. Acta Med Okayama. 2011;65(5):299-306.

59. Pedersen JS, Valen E, Velazquez AMV, Parker BJ, Rasmussen M, Lindgreen S, Lilje B, Tobin DJ, Kelly TK, Vang S, Andersson R, Jones PA, Hoover CA, Tikhonov A, Prokhortchouk E, Rubin EM, Sandelin A, Gilbert MTP, Krogh A, Willerslev E, Orlando L. Genome-wide nucleosome map and cytosine methylation levels of an ancient human genome. Genome Res. 2014;24(3):454-66.

60. Andrews S. FastQC: a quality control tool for high throughput sequence data. https://www.bioinformatics.babraham.ac.uk/projects/fastqc/. Accessed 1 August 2019.

61. Wood DE, Lu J, Langmead B. Improved metagenomic analysis with Kraken 2. Genome Biol. 2019;20(1):257.

62. Picard. http://broadinstitute.github.io/picard/. Accessed 8 September 2020.

63. Dudchenko O, Batra SS, Omer AD, Nyquist SK, Hoeger M, Durand NC, Shamim MS, Machol I, Lander ES, Aiden AP, Aiden EL. De novo assembly of the Aedes aegypti genome using Hi-C yields chromosome-length scaffolds. Science. 2017;356(6333):92-5.

64. DNA Zoo. https://www.dnazoo.org. Accessed 7 August 2019.

65. GenBank. https://www.ncbi.nlm.nih.gov/genbank/. Available from the National Center for Biotechnology Information. Accessed 7 August 2019.

66. Smit AFA, Hubley R, Green P. Repeat-Masker Open-4.0. http://www.repeatmasker.org. Accessed 15 August 2019.

67. Stephen S. kit4b. https://github.com/kit4b. Accessed 16 January 2020.

68. Li H, Handsaker B, Wysoker A, Fennell T, Ruan J, Homer N, Marth G, Abecasis G, Durbin N, 1000 Genome Project Data Processing Subgroup. The sequence alignment/map format and SAMtools. Bioinformatics. 2009;25(16):2078-9.

69. R Core Team. R: A language and environment for statistical computing. https://wwwRproject.org/. Accessed 19 September 2019.

70. Wickham H. ggplot2. https://ggplot2.tidyverse.org/. Accessed 20 November 2020.

71. Kassambara A. ggpubr. https://github.com/kassambara/ggpubr/. Accessed 20 November 2020. 